\title{
FRANCISCO DE VITORIA Y LA RAÍZ DEL DERECHO PENAL
}

FRANCISCO DE VITORIA AND THE ROOT OF THE CRIMINAL LAW

FRANCISCO DE VITORIA E A RAIZ DO DIREITO PENAL

Claudio Brandão

\section{Resumen}

El iluminismo penal fue forjado como la culminación de un proceso de quiebra de paradigmas. Esto se debió mucho a las posiciones de vanguardia que fueron construidas antes de su afirmación, especialmente aquellas del Derecho Natural racionalistas, que estaban en la base del pensamiento jurídico de la Edad Moderna. En ese contexto, las ideas penales de Francisco de Vitoria ganan una notable importancia para la comprensión de la matriz del Derecho Penal de estos días, pues ellas se vinculan al ya referido iluminismo. Tales ideas rompen el paradigma del medioevo y sustituyen el teocentrismo por el antropocentrismo en el campo criminal.

Palabras clave: Vitoria. Ley. Derecho Natural. Racionalismo. Pena. Costumbre. Culpabilidad.

\section{Abstract}

The penal enlightenment was forged as the culmination of a process of bankruptcy paradigms. This is much due to the forward positions that were built before its claims, especially those of natural law rationalists who were based on legal thought of the modern age. In this context, the criminal ideas of Francisco de Vitoria gain considerable importance for understanding the matrix of the criminal law of these days, because they are linked to the enlightenment. Such ideas break the paradigm of the middle ages and replaced in theocentrism by anthropocentrism in the criminal field.

Keywords: Vitoria. Law. Natural law. Rationalist. Penalty. Custom. Culpability. 


\section{Resumo}

O iluminismo penal foi forjado como a culminação de um processo de quebra de paradigmas. Isso se deveu muito às posições de vanguarda que foram construídas antes de sua afirmação, especialmente aquelas do direito natural racionalista, que estavam na base do pensamento jurídico da Idade Moderna. Neste contexto, as ideias penais de Francisco de Vitoria ganham uma notável importancia para a compreensão da matriz do direito penal hodierno, pois elas se vinculam ao já referido iluminismo. Tais ideias rompem o paradigm medieval e substituem o teocentrismo pelo antropocentrismo no campo criminal.

Palavras-chave: Vitoria. Lei. Direito Natural. Racionalismo. Pena. Costume. Culpabilidade.

\section{DIMENSIÓN DEL ESTUDIO Y OBJETO DE LA INVESTIGACIÓN}

El Derecho Penal liberal, de un Estado Democrático de Derecho, se caracteriza por la limitación al jus puniendi. Con esa limitación se protege a la persona humana frente al Estado y, con eso, se restringe la aplicación de la consecuencia penal - la pena - a través de una serie de requisitos previos a su aplicación. En efecto, tales requisitos fueron estructurados a partir del Siglo XIX en tres teorías que fueron y conforman la dogmática penal, las cuales son, la Teoría del Crimen, la Teoría de la Pena y la Teoría de la Ley Penal, que generalmente son apuntadas como resultantes del iluminismo penal, aunque con un desarrollo posterior autónomo. Debe hacerse notar que la cientificidad del Derecho Penal fue constituida a partir de la primera de esas teorías, esto es, la Teoría del Crimen, debido a que ella estructura una serie de instrumentos que diferencian la conducta penalmente relevante, los cuales también se presentan como obstáculos de la pena, revelándose, como criterios que limitan en sí mismo el poder de punir del Estado.

La doctrina es unísona al resaltar la contribución del Marquês de Beccaria, Cesare Bonesana, para la construcción de este dicho Derecho Penal liberal. Se apunta como un hito de esta fase, pues, la segunda mitad del Siglo XVIII, época en la cual fue editada la obra De los delitos y 
las penas, datada en 1764, de autoría de aquel noble. En este panorama, el Principio de la Legalidad, apuntado como la piedra angular de una sociedad unida a través del contrato social, traería consecuencias para la aplicación del Derecho Penal, pues sería decurrente de este principio, por ejemplo, la utilidad de la pena, la igualdad de las personas ante este Derecho (sin que se diferencien más nobles y siervos en la aplicación de la pena), la prohibición de la analogía, entre otras.

Debe notarse que no se clasifica la obra de Beccaria como de dogmática, pues su tesis sobre la limitación del poder de punir es definida en el ámbito de la filosofía política. Esto no significa, sin embargo, que al tiempo de él no hubiera una construcción propia sobre el Derecho Penal. Pese a que hoy la hoy utilizada tripartición de la Teoría del Crimen (tipicidad, antijuricidad y culpabilidad) se haya desarrollado a apartir del Siglo XIX, basados en los postulados de limitación al poder de punir del Estado que, como ya se afirmó, caracterizan el Derecho Penal del Estado Democrático de Derecho, en aquel tiempo los prácticos italianos ya habían consolidado una serie de instituciones. Solo para ejemplificar, cítese el Tractus Criminalis, de Tiberius Deciano, el cual presentaba, como base en las cuatro causas primeras aristotélicas, dichas instituciones. La causa formal del crimen era la lex, la ley positiva y la ley natural; la causa material del crimen era el dolo; causa eficiente del crimen era la acción. Y, por fin, la causa final del crimen eran los motivos. Pero Beccaria no se preocupó con el análisis de las instituciones penales en sí, tratándolas apenas de forma refleja, pues su obra, como él mismo afirmaba, se dirigía a la crítica de los déspotas subalternos, que se sentaban bajo el peso de las tiranías, utilizándose del Derecho Penal para afirmar su potestad.

En ese sentido, los investigadores del Derecho Penal no se preocupan, en general, de la investigación anterior de Beccaria. Se toma, pues, al iluminismo como el germen del Derecho Penal liberal, lo que, si no es algo totalmente equivocado, se presenta com una afirmación, por lo menos, incompleta. Conforme señala Silvia Alves, el humanismo contribuyó al nacimiento de una parte general al delinear una dirección sistemática y sintética para el derecho penal (ALVES, 2014, p.7), luego se ve que el iluminismo penal ya encontró, al venir, una sólida gama de teorizaciones sobre el derecho penal. 
En efecto, el iluminismo penal no surgió de la nada. Al contrario, él se presentó como el resultado de un proceso que tiene en su raíz al Derecho Natural racionalista, que, por su parte, dio al jurista actual la base de las instituciones penales que hoy son utilizadas una vez que esta última corriente se preocupó mucho menos con la filosofía política pues fue dirigida para dar respuestas concretas a los problemas jurídicos que precisaba enfrentar en su época.

Pues bien, entre los pensadores del Derecho Penal del Derecho Natural racionalista, tiene especial importancia el salmantino Francisco de Vitoria, debido a que él anticipa posiciones, instituciones y consecuencias que solamente serán consolidadas en los Siglos XIX y XX. Por la obra de Vitoria, constatamos que mucho de lo que se presentó como vanguardia del pensamiento contemporáneo en realidad es algo ya antes construido y defendido, con base en el criterio de la dignidad de la persona humana, que es el soporte común entre el Derecho Natural racionalista y el Derecho Penal liberal. Investigar el pensamiento penal de Vitoria es el objeto de este trabajo.

\section{EL HUMANISMO DEL SIGLO XVI Y EL CONTEXTO DE LA OBRA DE VITORIA}

El Siglo XVI fue el palco del nacimiento y del desarrollo del humanismo. La recomprensión del conocimiento antiguo despreciado por el mundo medieval posibilitó el nacimiento de esa nueva corriente de pensamiento, que se emancipó de las tradiciones medievales y que tenía preocupaciones prácticas, valorizando al hombre como centro y destinatario del conocimiento, pues ella se dirigía a los problemas de su centro, en particular la persona humana. Esa emancipación es muy diferente a la de las escuelas del medioevo, cuyo pensamiento especulativo no raro se disociaba por completo de la vida práctica, colocando sus raíces en la metafísica (VILLEY, 2009, p.437).

El humanismo, por tanto, no fue concebido como un pensamiento original, sino, representó un reencuentro con elementos de la filosofía antigua, especialmente de la antigüedad tardía, como el ceticismo, el epicurismo y, en alguna medida, el estoicismo, despreciados por la cultura 
medieval teocéntrica. Así también el humanismo representó el reencuentro y la recomprensión de la cultura clásica (MEDER, 2008, p.191).

Villey al hablar sobre esa época dice que: "Precisamente, en el siglo XVI, renace una cultura profana. Un nuevo campo de investigación se abre delante de todos nosotros: todo el humanismo, Rabelais, Montaigue, Erasmo, Vivès, Justo Lípisio; y alrededor de ellos una enorme cantidad de nombre más o menos olvidados; y, por intermedio de ellos otros autores que ellos hicieron revivir, pues el producto del esfuerzo de ellos es un Renacimiento. Más que engendrar doctrinas originales, la obra del humanismo fue sobre todo la de los eruditos que reencontraron a los filósofos que representaron y revalorizaron filosofías antiguas que la cultura medieval despreciara. Se trata principalmente de las doctrinas helénicas, productos tardíos de la Antigüedad, posteriores al descenso de Atenas y a las grandes conquistas de Alejandro, transmitidas por los autores latinos - como el estoicismo, el cetismo y el epicurismo." (VILLEY, 2009, p.435)

Debe resaltarse que el pensamiento humanista trascendió el Derecho en mucho, verificándose en diferentes sectores de la enciclopedia del conocimiento. Pero en el plano jurídico, el primer impulso sistemático del humanismo fue dado en Francia y tenía como objetivo directo la crítica al pensamiento jurídico medieval, el cual se desarrolló en Italia, tanto así que fue denominado de mos italicus, que ganó eco en la escuela medieval de los Pos-glosadores (1250-1400). El mos italicus, en su fase final, se caracterizaba por el abuso de los argumentos de autoridad, dispensando la justificación del pensamiento por los argumentos racionales y eso estaba en la raíz de la crítica de los humanistas. Por haber surgido en Francia, el método de estudio del derecho de esta escuela es llamado de mos gallicus ${ }^{1}$.

Los juristas de la escuela de los humanistas volvieron al estudio de las fuentes del derecho (BRANDÃO, 2012, p.156). Así, no se buscaría más, como fin metodológico, la búsqueda de la opinión común de los doctores, sino la comprensión tanto del contexto cultural como del significado textual de la compilación justinianea. Esto llevó a los referidos humanistas al reencuentro de la cultura clásica, que hizo con que el investigador se encontrara con un sistema de elaborada utilización de argumentos lógicos, 
expresados, desde la comprensión de las instituciones jurídicas con base en la razón. El producto de esta búsqueda "fue un cambio en la mentalidad del jurista, que ya no concebía al derecho romano como derecho actual, sino como elevada creación del genio romano y, por tanto, como expresión histórica de la razón y de la equidad, pero no necesariamente la única" (LEVAGGI; 1991, p.98).

El Derecho Romano dejó de ser considerado como revelación del Dios y paso a ser tenido como un conocimiento datado, que no pertenecía más a aquella realidad histórica ${ }^{2}$, a pesar de que fuera tenido como un sistema altamente racionalizado, dirigido al propio fin de aquel derecho: la búsqueda de la decisión buena y justa. La compilación justinianea tenía un valor intrínseco como conocimiento que conducía a la equidad, pero no debía ser aceptada como dogma. La razón humana es la que posibilitará el uso del Derecho Romano, el cual deberá ser utilizado como un instrumento en la búsqueda de la justicia del caso concreto y de la buena decisión, actividad racional, dirigida por las facultades del hombre. De este modo, defendían que el conocimiento del derecho no se adquiere solo a través de la lógica y de la dialéctica, sino también a través de los medios filológicos, históricos, literarios, en resumen: a través de las humanidades (BRITO, 1978, p.37).

El humanismo se propagó en los países protestantes, como Holanda y Suiza. Pero, debemos registrar su influencia en países católicos como, en particular, España, y entre pensadores católicos, como el inglés Tomas More.

Fueron Francisco de Vitoria y Francisco Suárez los grandes representantes de este humanismo español, también llamado de Escolástica Tardía española, que se volvía al antropocentrismo jurídico. Con el cambio de Suárez a la Universidad de Coimbra ${ }^{3}$, el humanismo español se vinculó más aún a Francisco de Vitoria, siendo él su mayor representante.

Francisco de Vitoria estudió en París, en la primera mitad del Siglo XVI, habiéndose recibido de doctor el 27 de junio de 1522. De forma nada convencional, antes de obtener el doctoramiento, fue designado por el Capítulo General de la Orden Dominica, a la cual pertenecía, para la docencia de Teología. En efecto, el Capítulo General realizado en Nápoles, en el año 1515, atribuyó a Vitoria el encargo de leccionar en París el Liber sentenciarum, de Pedro Lombardo ${ }^{4}$. Los siete años que pasó 
como leyente en París, puso a Vitoria en contacto con el humanismo, que mucho más asimilado, fue desarrollado por él de forma original, sobre todo dirigido a los problemas concretos con los cuales se deparó a su vuelta a España y, en especial, durante el ejercicio de su cátedra en Salamanca. Fue la adhesión a esa corriente lo que "lo llevó a tomar en sus manos la defensa de la justa causa de los indios. Abordando la materia cruel del derecho de guerra, Vitoria afirmó principios de moderación y mansuetud. Casi todo el movimiento pacifista del siglo XVI procedía del humanismo y este actuará sobre el pensador español dando secuencia a su actuación en la iglesia, ya desde tiempos anteriores. En 1520, durante su estadía en París, Francisco mantuvo contacto con Josse van Assche, Jodocus Badius Ascensius, una de las mayores expresiones del humanismo" (CASELLA, 1985, p.358) ${ }^{5}$.

Fue al tratar de los problemas jurídicos que Francisco de Vitoria afirma al hombre como el centro y destinatario de la lex. La conquista de nuevas tierras hace con que una serie de cuestiones jurídicas viniesen al asunto, entre las cuales una sobresale: ¿los habitantes de aquellos territorios, que estaban en un estado civilizatorio poco evolucionado, eran sujetos de derechos? Sobre todo gana importancia esa pregunta, a la luz de la cultura de la época, si son considerados en su condición de "bárbaros", esto es, sujetos que no profesan el cristianismo. En efecto, los más importantes problemas que debían ser resueltos por esta corriente vinieron por la conquista del Nuevo Mundo, ya que el corpus christianum medieval no traía respuestas a las cuestiones advenidas de esa conquista (MAIHOLD, 2005, p.48).

Francisco de Vitoria enfrentó aquella pregunta con los lentes del humanismo. El equipar jurídicamente cristianos y paganos, en razón de la pertenencia a una comunidad de naciones y en razón de la naturaleza humana del ser, hizo con que las personas - ahí incluidos los indios fueran, dentro de su doctrina, vistos como sujetos de derechos. De este modo, "su preocupación fue, sobre de todo, con el hombre y sus derechos inalienables" (AZEVEDO, 2008, p.128).

Debido a que la preocupación central de Vitoria era el hombre, en sus lecciones, él no fue silente a los problemas decurrentes del Derecho Penal. En efecto, las cuestiones que gravitaban en torno de la pena apli- 
cada al hombre fueron una preocupación del salmantino, originando un pensamiento que, en el ámbito de la dogmática, confiere al humanismo el carácter de matriz del Derecho Penal liberal. Debe notarse que, cuando se habla en el campo de la dogmática, está tratándose de las Teorías del Crimen, de la Pena y de la Ley Penal, y es en esa área que Vitoria se diferencia de Beccaria. En efecto, mientras el segundo trató de las bases limitadoras del poder de punir en el campo de la filosofía política el primero trató del Derecho Penal referido a los problemas concretos, esto es, refiriéndose a las instituciones penales existentes en su época.

\section{LAS IDEAS PENALES DE FRANCISCO DE VITORIA}

Francisco de Vitoria no despreció la cultura medieval, aunque la re-compendió a la luz del antropocentrismo. Así, aunque la Universidad de Salamanca tuviese en sus estatutos normas que establecían que la Cátedra Prima de Teología se diese a partir de las Sentencias de Pedro Lombardo, Vitoria guio sus enseñanzas basado en la Suma Teológica de Tomás de Aquino (STÜBEN, 2011, p.7) ${ }^{6}$. Por eso se dice que la teoría penal de Tomás de Aquino fue recibida por la obra de Francisco de Vitoria ${ }^{7}$. En lo que se refiere al Derecho Penal, el salamantino no despreció las concepciones teológicas y morales construidas en la Edad Media, pues comprendía las violaciones penales que estaban encima de todo como un pecado y su respuesta como una doctrina ética (eudemonismo), que quiere, sobre todo, la felicidad del hombre, tanto en este mundo como en el mundo sobrenatural (STIENING, 2011, p.133). Pero esas violaciones eran interpretadas bajo una dignidad especial que se confería al autor de esas violaciones porque se lo consideraba el destinatario final del propio Derecho.

Además, debe notarse que en el pensamiento penal del salmantino: "La escolástica tardía española (de la cual Vitoria es el protagonista) y su doctrina del derecho natural, que posteriormente fue asimilada por Hugo Grotius en el periodo de la doctrina alemana del derecho natural y por el idealismo alemán, tuvo un papel determinante en la sistematización de concepto de pena". ${ }^{8}$

Con toda razón, pues, se apunta a la gran influencia que las ideas penales propuestas por Vitoria, las cuales se propagan en Hugo Grotius, 
el mayor representante de la doctrina del derecho natural alemán, y en el pensamiento penal del idealismo alemán. Así, la conceptuación de la pena a la culpa, que están en el centro del derecho penal propuesto por el salmantino, recorren los siglos hasta el aparecimiento del sistema dogmático tripartido del Siglo XIX.

\subsection{PANORAMA CONCEPTUAL DE LA LEY}

La obra en la cual Vitoria enfrenta cuestiones del Derecho Natural y del Derecho Penal,

De legibus, viene a la luz el año académico 1533/1534, antes de la famosa relectura del salmantino sobre los indios (ésta de 1539), cuyo tenor crítico inauguró una nueva fase en la política colonial española9 En ella, Vitoria parte de la tripartición utilizada por Tomás de Aquino, es decir: Ley Eterna, Ley Natural y Ley Humana, para dar una interpretación revolucionaria para la época, la cual será el hilo conductor para su reflexión moral sobre los indos y sobre el derecho de todas las gentes. En efecto, la teoría de la ley de Vitoria permitió la justificación en el plan teórico de la concepción subjetiva (rectius, perteneciente a todo ser humano) del Derecho, el que se debe a su concepción de ley natural.

En este panorama, la esencia de la ley es presentada como un algo que pertenece a la razón, pues, mientras la regla y la medida de los actos humanos, su etimología provienen de obligar (legare), y el mando es un producto de la razón, ya que reside en el intelecto. Vitoria se expresa así sobre el tema: "ARTÍCULO PRIMERO - si la ley es algo propio de la razón o reside en la razón y en la voluntad. Responde que la ley es algo que pertenece a la razón, porque a ésta le corresponde mandar; y la ley es la regla y la medida de los actos, y se dice que la ley por su propia procedencia de 'relacionar', porque obliga. Es evidente, pues, que la ley se localiza en la naturaleza racional y, en consecuencia, no puede fundarse sino es en la sensibilidad o en el intelecto. Y no reside en la sensibilidad. Luego..." (VITORIA, 2010, p.88)

Con esta afirmación, Vitoria refuta la posición afirmada en el Medioevo de que la ley sale de la voluntad divina, luego era producto, al final, de la voluntad. El salmantino nos dice que la ley es un mandato, y como 
tal está determinado por la razón y ordenado a un fin, lo que solo puede tener su origen en la actividad racional. Como regla, la ley es ordenada hacia un fin, por tanto ella siempre deberá ser ordenada a la afirmación de un bien común ${ }^{10}$. Debe notarse que esa destinación al bien común viene de la propia naturaleza de la ley y no de la voluntad del legislador, pues cuando cesa el bien común también cesa la ley, ya que este último integra la substancia de la propia ley. Así, la ley es identificada como un mandato de la razón ordenado al bien común, que obliga.

Sobre la esencia de la ley, concluye con precisión Langella: “En esta definición se recogen los elementos esenciales de la ley, definición que no es exclusiva de ninguna ley entre las distintas clases de ley en particular, aunque sea válida para todas. La ley es una orden de la razón, es una regla, norma o medida de todos los actos, por medio de la cual se estimula al hombre a actuar o no actuar. Es un mandato obligatorio y, como tal, no solamente indica el camino, sino da una orden que se debe seguir" (LANGELLA, 2010, p.35).

Para finalizar, se debe resaltar las divisiones de la ley para Vitoria. La Ley Eterna es tenida como producto directo de los designios de Dios, que todo rige. Dios es el sumo legislador y de él proviene la lex aeternae, que gobierna todas las cosas. Pero Dios no está sometido a ella (VITORIA, 2010, p.119). Porque todas las artes inferiores se subordinan a las superiores, la Ley Eterna es tenida como un fundamento tanto de la Ley Natural, como de la Ley Humana. La Ley Natural, aunque no sea un hábito, se mantiene por el hábito, ella da condiciones por la inclinación de la naturaleza, al juzgar la rectitud de todas las cosas ${ }^{11}$, también siendo fundamentada en la razón (SPINDLER, 2011, p.49), ya que ella se basa en la reflexión humana acerca de la Ley Eterna.

En ese sentido se nota que "Los teólogos españoles (de la Escolástica Tardía) definen la base de la ley natural, sobre todo, por la teoría de Tomás de Aquino, según la cual los preceptos de la ley natural vienen de la reflexión terrena acerca de la ley eterna de Dios"12.

La Ley Humana, si es justa, procederá de la Ley Natural. Dichas leyes "se ordenan al bien común, deben establecerse para la comunidad y perdurar en la comunidad política” (VITORIA, 2010, p.135). A su vez, la Ley Humana se subdivide en Ley Eclesiástica y Ley Civil. La primera es la ley 
de la Iglesia, la segunda la ley del Estado. Debe notarse que la Ley Civil no se confunde, en el pensamiento de Vitoria, con la ley del derecho privado, pues el jus civile es tomado en la acepción romana, como derecho del ciudadano. En este contexto, la ley de naturaleza penal, integra el jus civile.

\subsection{APROXIMACIÓN VALORATIVA DEL CONCEPTO DE BIEN JURÍDICO}

Vitoria ya presenta la idea de valoración cuando afirma que toda la ley debe ser ordenada para el bien común. Pero esa idea general puede ser subsumida de la ratio del bien jurídico penalmente tutelado. En efecto, el bien jurídico surgió cuando se reflexionó sobre el objeto del Derecho Penal. Inicialmente, al inicio del Siglo XIX, Ansel von Feuerbach defendió que la función del derecho penal era la tutela de intereses, que eran los derechos subjetivos, como el derecho a la vida, el derecho a la propiedad (FEUERBACH, 1989, p.64), etc. Esta noción fue sometida a una profunda crítica que originó el instituto del bien jurídico. Birnbaum decía que el derecho subjetivo residía en la esfera interna del hombre ya que él pertenece a una persona; así, no podría ser subjetivo u objetivo dicho derecho de la tutela penal. En este panorama, lo que es el objeto de la tutela penal es un bien (BIRNBAUM, 1934, p.175) esto es, un valor objetivo; por ejemplo, no se tutela penalmente el derecho a la vida, sino la propia vida. El valor tutelado por el Derecho Penal es un bien porque existe de manera autónoma en relación al derecho subjetivo que eventualmente es generado por él, con el objetivo de la pertenencia de ese bien a un sujeto de derecho.

Debe notarse que Vitoria en esa misma línea de pensamiento, indica que no es la Ley Humana la que confiere el carácter de bien o de mal al objeto tutelado. El autor dice que el mérito o el desmérito de algo reside en el hecho de ser bueno o malo, pero quien convierte algo en bueno o malo es la Ley Divina, cuyo autor es exclusivamente Dios. De esta forma, Vitoria defiende la existencia de una valoración en las cosas que se extrae de forma independiente de la Ley Humana, pues se atribuye de forma lógicamente independiente de ella (por la Ley Divina) un signo positivo (calificando la cosa como un bien) o un signo negativo (calificando la cosa como un mal). 
El salmantino nos dice: "pues el fundamento del mérito o del desmérito de algo reside en que él sea bueno o malo. Por consiguiente, lo primero que hace la ley divina es convertir en bueno o malo lo que en sí mismo era indiferente. (...) La circuncisión era indiferente y se transformó en algo bueno mediante la promulgación de una ley." (VITORIA, 2010, p. 139).

Debe notarse que cuando se reconoce un valor que existe en referencia a la propia naturaleza de la cosa, de tal modo que la califica de forma autónoma como buena o mala, se está diciendo que el bien calificado como bien es susceptible a ser violado. Aunque esa sea la raíz que está en el concepto del bien jurídico penal. Cuando Vitoria desvincula de la Ley Civil la naturaleza buena o mala de los objetos, él nos dice, al contrario del pensamiento común, que tal naturaleza existe de forma independiente de la Ley Civil. Tal afirmación tiene un alcance extraordinario porque Vitoria justifica en el plano teórico (sobre todo en la relectura De Indis) el pasaje de una concepción objetiva a una concepción subjetiva de derecho, incluyendo ahí la Ley Natural. Al reconocer la naturaleza independiente del objeto tutelado por la Ley Humana, él está separando de la esfera del derecho subjetivo un valor presente en la sustancia de las cosas, consideradas en su esencia, que es susceptible de violación.

Pues bien, ese juicio de valor independiente y objetivo (el bien jurídico) será desarrollado en el Siglo XIX como un instrumento de limitación de la ley, y posteriormente será tenido como un fundamento de toda la aplicación supra-legal, en beneficio de la parte, del Derecho Penal. Pero, debe resaltarse que de Vitoria se extrae solamente una aproximación de fundamentos, no el concepto de bien jurídico explícitamente dado. Además, no deja de ser digno de mencionar que tres siglos antes, ya se intuía, al analizar la ley, que el valor de las cosas está en su substancia, independiente del acto de poder que regula ella misma.

\subsection{LA COSTUMBRE COMO FUENTE DE DEROGACIÓN DE LA LEY PENAL.}

Fue solamente después de la consolidación del Principio de la Legalidad como un principio rector del Derecho Penal de los Estados Democráticos de Derecho que se afirmó que él es una protección del hombre 
en referencia al jus puniendi estatal. De esta forma, el Principio de la Legalidad tienen una ratio pro libertatis, sirviendo para aumentar el ámbito de libertad, al restringir explícitamente el ámbito de la punición.

En este contexto, se defendió la fuerza de la costumbre para derogar los tipos penales anacrónicos, que no estaban en el compás de la realidad social. En efecto, si el Principio de la Legalidad prohíbe la aplicación de la costumbre como fundamente de una incriminación, esto es, la costumbre im malam partem, por la misma ratio admite la costumbre que genera efectos en beneficio de la parte. La costumbre que aumenta el ámbito de libertad será, teleológicamente conforme al Principio de la Legalidad. La eficacia de la costumbre a la luz del Principio de la Legalidad se dará, conforme en el Siglo XX afirma Maysach, para apartar los tipos penales que no representen coherencia con la sucesión de actos de una época, siendo tenidos como anacrónicos.

Como nos dice Mauarach: "La eficacia derogativa del derecho consuetudinario constituye, en la vida jurídica, un medio imprescindible para la expulsión de amenazas de pena que llegaron a ser obsoletas y que el legislador no derogó formalmente por imprudencia o por imposibilidad" (MAURACH \& ZIPF, 1994, p. 139).

Lo que hoy se presenta como una garantía dada por la utilización del Derecho Penal según una metodología de un Estado Democrático de Derecho, por colocar a la persona humana como centro de la dogmática penal aplicada, fue definido por Vitoria según la misma postura dirigida a la persona humana. Es bueno notar que en su obra sobre la ley, Vitoria aclara que la costumbre tiene fuerza de para obligar, derogando la ley por el desuso.

En este sentido, el salmantino dice: "ARTÍCULO TERCERO.- Si la costumbre puede tener fuerza de ley y obligar. Responde que sí y explica cómo el legislador puede manifestar su voluntad no solamente con palabras, sino también de hecho, como por ejemplo se deja de castigar a los transgresores de una ley, esta queda derogada por la costumbre." (VITORIA, 2010, p.161)

Debe notarse que Vitoria completa el pensamiento, consignando a que si la costumbre establece que sea buena la realización de una conducta no le compete al legislador prohibirla. También nos dice que 
cuando existe desuso la regla del legislador no tiene fuerza de ley (VITORIA, 2010, p.163).

Así, Vitoria concluye su pensamiento diciendo que: "En el último capítulo acerca de la costumbre se dice expresamente que toda costumbre prolongada, contraria a una ley humana, deroga la ley, porque no es despreciable la autoridad de una costumbre larga (quia longavae consuetudinis non est contemnenda auctoritas) (VITORIA, 2010, p.163).

Debe notarse que las leyes que castigan, vistas como caso límite del raciocinio del Salmantino, justamente por el castigo infringido, tiene naturaleza penal. Así, al traer en última instancia la derogación del castigo previsto en la ley, por la costumbre, Vitoria también limita, con esto, el poder de punir. Es digno de reflexión que aquello que es presentado como uno de los pilares del método penal actual, que es el uso de la desuetudo para derogar la ley penal, como consecuencia del Principio de la Legalidad aplicado a la costumbre (nullumm crimen nulla poena sine lege scripta), ya fue defendido desde el Siglo XVI como producto de una noción de ley centrada en el hombre, lo que revela la vanguardia de este pensamiento.

\subsection{RELACIONES ENTRE LA PENA Y LA CULPABILIDAD}

Vitoria defiende explícitamente que la culpa penal sale del prejuicio legal. En efecto, en una teorización en la cual la ley se dirige a la persona, teniendo en su núcleo la racionalidad ya que se fundamenta en el intelecto y no en la voluntad, es una consecuencia que la censura sobre alguien sea un requisito para la aplicación de la pena. Decir que las leyes determinadas obligan en referencia a la culpabilidad, es decir que las leyes obligan en referencia a la pena que se impone a la violación de un imperativo, el cual convierte obligatorio un determinado comportamiento.

Así nos dice explícitamente el salmantino: "Por último aparece la duda si se obligan fundamentadas en una culpa las leyes penales, esto es, las leyes penales que establecen una pena determinada. (...) Enrique Gandavese dice que a su vez las normas penales cuenten tanto un precepto como la pena, (...) otras veces solo establece la pena. La primera fórmula obliga fundamentada en una culpa, la segunda no. Sigue esta opinión la Summa Angelica." (VITORIA, 2010, p.149). 
Debe resaltarse que en el texto original Vitoria hace uso de la sentencia latina an obligent ad culpam, lo que relaciona el problema penal al problema del pecado. La culpabilidad de que habla Vitoria es aquella vinculada a las modalidades teológicas de pecado venial o de pecado mortal y esto indica que Vitoria está relacionando la pena a la censura personal.

No podemos olvidar que el concepto de culpabilidad adviene de la traducción del vocablo alemán Schuld, que indica la deuda del pecado (palabra, es decir, también usada en la lengua alemana en la oración del Padre Nuestro, como sinónimo de ofensa).

Debe notarse que toda la construcción alrededor de la relación entre culpabilidad y pena está influenciada por la teología. Si no veamos: el local en el cual el culpado cumple la pena es llamado de penitenciaría, vocablo que viene de la palabra penitencia, esto es, la satisfacción que debe ser dada por la explicación de la culpa. El local en el cual el preso cumple la pena privativa de libertad es llamado de celda, tal nombre también es atributo para el cuarto en el cual viven los monjes y allá realizan la penitencia. La penitencia es impuesta, teológicamente en el sacramento de la confesión; no es de extrañarse pues que la confesión haya sido tenida durante todo el Siglo XIX y parte del Siglo XX como la reina de las pruebas, sobre todo si notamos que ese tiempo es en el cual se tienen las primeras teorizaciones sobre la culpabilidad como elemento del crimen.

Al vincular la pena a la culpa, en el campo de la ley penal, Vitoria indica la necesidad de que se fundamente el mal de la pena en la censura que debe ser hecha al agente. Esto, en el plano teológico aplicado al pecado, es decir, ya era extraído del manual de los penitentes y posibilitaba la gradación de la penitencia aplicada por el sacerdote al conferir el sacramento. Ocurre que esa defensa anticipará la sustancia de lo que hoy es presentado como una conquista del Derecho Penal del Estado Democrático de Derecho.

Jescheck, al tratar de la culpabilidad a la luz de la jurisprudencia del Tribunal Federal alemán, nos dice: "La pena requiere la culpabilidad antes. La culpabilidad es re-probabilidad. Con el desvalor de la culpabilidad se censura al autor por no haberse comportado conforme al derecho, sin que se haya decidido por él, cuando podía comportarse conforme a él, cuando podía decidirse por él". 13 
De hecho, no existe diferencia entre la sustancia de lo que Vitoria enseña y la actual relación entre la pena y la culpa, ejemplificada aquí a través de la obra de Jescheck, ya que la reprobación personal de la que habla Jescheck es la misma censura de la culpa, traída por Vitoria.

En este panorama, los dos autores establecen que la culpabilidad es, lógicamente, la causa de la pena, pues ella representa un requisito para la aplicación de la sanción penal. Es por este motivo que ambos vinculan la pena a la cuestión de la culpa, pues la primera es tenida como un sufrimiento, que solo se justifica si se impone en referencia a una satisfacción debida por el agente por cuenta de un crimen. Tal contenido, en ambos autores, es nítidamente expiatorio, lo que traduce la raíz religiosa presente en esas instituciones.

\section{CONCLUSIÓN}

Vitoria no nos presenta un conocimiento sistemático del Derecho Penal. Al contrario, el poder de punir, la ley penal y lo que viene de sus aplicaciones, están colocados en partes esparcidas de sus teorizaciones, llenas de fundamentación teológica. Pero, al buscar dar una solución a los problemas de la época, el salmantino trata de cuestiones concretas, aplicables para la solución de lides y, con esto, se encuentra en él la concretización del mismo objetivo del conocimiento denominado hoy de dogmática penal: la resolución de casos concretos.

Sin despreciar el conocimiento medieval, sino realizando una interpretación de aquel conocimiento bajo el nuevo prisma: el humanismo, generó un sistema de conocimiento interdisciplinar que consagró las formas política, teológica, moral y jurídica a un solo tiempo y, con eso, no tuvo por objetivo delinear las cuestiones de las instituciones jurídicas penales vistas en sí mismas. Pero, al solucionar los problemas penales de la época, de forma refleja revolucionó dichas instituciones.

Sus teorías, al ser interpretadas por las escuelas del Derecho Natural alemán y del Idealismo Alemán, pudieron llegar, aunque en muchos términos reflejamente, al periodo de construcción de la dogmática científica de la Teoría del Crimen. Póngase en relevancia que tal periodo se dio a partir del Siglo XIX, con la consolidación del Principio de la Legalidad, 
a través de la Teoría de la Coacción Psicológica de Feuerbach, como el principio rector del Derecho Penal liberal.

El gran hito que puede ser atribuido a Vitoria, en el área penal, es la colocación del hombre visto como el destinatario y centro del derecho, como el soporte en el cual deben ser resueltos los casos que él se pone a solucionar. Al colocar las cuestiones de la vinculación de la pena a la culpa, o de la posibilidad de derogar la ley penal por la costumbre, el salmantino anticipa soluciones que son tenidas como posiciones de vanguardia del Derecho Penal del Estado Democrático de Derecho. Como en su época no había siquiera ese concepto político de estado, la solución final que él presenta, por preocuparse en conferir dignidad a la persona humana, nos muestra que es ese el fundamento - hoy traducido en principio jurídico - que está en la raíz del Derecho de aquel Estado.

Conforme también se desprende de las posiciones del salmantino acerca tanto de la eficacia derogativa de la costumbre en el derecho penal, como de las relaciones entre la culpa y la pena, los problemas penales concretos son resueltos en función a criterios que ponen en relevancia al hombre frente al poder de punir, en la medida en que se apartan puniciones a partir de una justificación que lleva en cuenta criterios que aumentan la esfera de libertad (criterios pro libertatis), con la restricción del ámbito de punición.

Es digno de nota que el contexto jurídico en el cual Vitoria escribe sus ideas penales es el jus omnes Gentium, esto es, el Derecho de todas las gentes. La pertenencia al género humano es, pues, la clave interpretativa para que las instituciones penales sean aplicadas a los casos concretos, según se desprende del pensamiento salmantino. Su teorización penal, a la luz de ese contexto jurídico, surgió refiriéndose a un Derecho Internacional en formación y se fundamentó en el destinatario del castigo, ya que existe en él la relación de pertenencia al género humano. En el panorama jurídico actual, como que de forma cíclica, el Derecho Penal vuelve a desarrollarse en el área internacional, sobre todo, con la continua afirmación del Tribunal Penal Internacional, y los problemas que se ponen en ese "noble" campo convergen hacia la misma sustancia apuntada por Vitoria: la reprobación del hombre. Urge, por consiguiente, que recorramos la misma llave interpretativa apuntada. 


\section{En ese panorama, el pensamiento de Vitoria está en la matriz de la dogmática penal contemporánea, no por haber delineado las institucio- nes penales en sí mismas, sino por haber revelado su sustancia, su más esencial fundamento: la protección en el campo penal de la dignidad de la persona humana.}

\section{NOTAS}

1 Debe registrarse que los precursores de los humanistas son los juristas italianos, entre ellos Petrarca y Bolognini. El método de estudio de los humanistas tiene su origen en Italia, pero el desarrollo de la escuela dio, innegablemente, en Francia. Por cuenta de la importancia de los predecesores del humanismo, hay quien defienda que la escuela se inició en Italia, aunque reconozca que su fase aurea se dio en Francia. Verbis: "Mos gallicus is the name given to a school of legal humanists who adopted a philological and historical approach in their study of Law. This school began in Italy with Petrarca, Ambrose of Camaldoli, Filelfo, Maffeo Vegio, Lorenzo Valla, Angelo Poliziano, Ludovico Bolognini, and others, but was raised to its gratest splendour by French authors like Andreas Alciatus and Jacques Cujas." (RIDDER-SYMOENS, 1992, p.392)

2 "Los humanista, en consecuencia, dejaran de considerar al Corpus Iuris un texto dogmático y lo miraron como una obra histórica, es decir, como una fuente de conoscimiento del derecho clásico". (BRITO, 1978, p.36)

3 Regístrese que también se atribuía a esa corriente el término de Escolástica Tardía Ibérica, porque también alcanza al pensamiento de Suarez, que se transfirió a Portugal. (MAIHOLD, 2005, p.42).

4 Debe resaltarse que el Capítulo de Génova, de 1513, ya había designado a Francisco de Vitoria para la docencia en el curso de artes, lo que se dio apenas un año después de la conclusión de sus primeros estudios en París. El curso de artes era destinado a aquellos que se preparaban para profesar los votos religiosos en la propia orden, como oradores.

5 El autor también anota que "O nome de Francisco de Vitoria aparece no frontispício de dois sermões de Cavarrubias, indicando que ele reviu a obra. Outros fatores vem demonstrar que Francisco de Vitoria não era um estranho à 'República das Letras', como é costume chamá-la, formada já em 1516 e da qual Erasmo de Rotterdan era o chefe reconhecido. Francisco não escondia seu entusiasmo pelo humanismo renascentista e, da parte de Erasmo, conservou-se carta dirigida a Francisco em que esta fala como reverência a respeito da teologia escolástica." (Idem. Ibidem).

6 También Langella dice sobre o tema, que "La elección de la Summa como texto-base para sus lecciones, hecha durante su magisterio en Paris, consolidada posteriormente en Valladolid, llega a ser definitiva a partir de 1526 y constituye la característica fundamental de su enseñanza. (...) En pocos años la innovación introducida por Vitoria fue adoptada por sus mismo colega, a pesar de que los Estatutos ordenaran la lectura de las Sentencias" (LANGELLA, 2010, p.19).

7 Cítese como ejemplo Schlosser y Willoweit, que inician el estúdio de la teología de la pena bajo la rúbrica: "Sobre a Teoria Penal de Tomás de Aquino e a sua recepção na escolástica tardia espanhola: o exemplo de Francisco de Vitoria". En el original: "Zur Straftheorie von Thomas von Aquin und ihrer Rezeption in der spanischen Spätscholastik: das Beispiel Francisco de Vitoria". (SCHLOSSER \& WILLOWEIT, 1999, p.313).

8 Traducción libre de: „Die Spanische Spätscholastik un Naturrechtslehre, die durch Hugo Grotius an die deutsche Naturrechtslehre und an den deutschen Idealismus weitergegeben wurde, hat bei der Systematierung des Strafberiffes eine masßgebliche Rolle gespielt" (MAIHOLD, 2005, p.2).

9 Sobre el tenor crítico de esta relectura, debe mencionarse la observación de Teixeira "Sabe-se que os textos de Vitoria, muito provavelmente, seriam incluídos no Índice de livros proibidos, não fosse o falecimento do Papa Sexto V. O período é conturbado, e o próprio imperador Carlos V, tendo a ameaça dos turcos por um lado e a ameaça protestante por outro, dignou-se somente a escrever 
ao prior dos dominicanos, Domingo de Soto, indicando que fosse proibida aos clérigos qualquer manifestação de opinião a respeito da política ultramarina do reino" (TEIXEIRA, 2011, p.225).

10 Nos dice Vitoria: "Responde que toda ley debe ordenarse al bien común. Lo prueba porque el fin de todas las leyes es la felicidad y hay otros fines que se ordenan a éste." (VITORIA, 2010, p.93). El bien común, como fundamento del poder civil es encontrado también en De Potestate Civili. (VITORIA, 2008, p.23).

11 Nos dice Vitoria: "Y, de este modo, alguna vez la misma ley se llama hábito, no porque sea habito, sino porque mediante él se mantiene. (...) La ley natural no se llama así porque exista en nosotros por naturaleza, pues los niños no tienen ley natural ni hábito alguno, sino porque por inclinación de la naturaleza juzgamos la rectitud de todas las cosas, no porque esa cualidad se halle en nosotros por naturaleza" (VITORIA, 2010, p.123).

12 Traducción libre de: „Die spanischen Theologen setzen für die Grundlegung des Naturrechts zumeist auf die Lehre des Thomas von Aquin, wonach die Gebote des Naturrechts der irdisches Abglanz des ewigen göttlichen Gesetzes" (MAIHOLD, 2005, p.49).

13 Traducción libre de: „Strafe setzt Schuld voraus. Schuld ist Vorwerfbarkeit. Mit dem Unwerturteil der Schuld wird dem Tater vorgeworfen, dab er sich nicht rechtmäbig verhalten, dab er sich für das Unrecht entschieden hat, obwolhl er sich nicht rechtmäbig verhalten, sich für das Recht hätte entscheiden Können“ (JESCHECK, 1988, p.19).

\section{REFERENCIAS}

ALVES, Sílvia. Punir e humanizar: o direito penal setecentista. Lisboa: Fundación Calouste Gulbenkian y Fundación para la Ciencia de Tecnología. 2014.

AZEVEDO, Luiz Henrique Cascelli de. Jus Gentium em Fancisco de Vitoria. Porto Alegre:Fabris. 2008.

BIRNBAUM, Johann Michael Franz. "Ueber das Erfordeniss einer Rechtsverletzung zum Begriffe der Verbrechens". Archiv des Criminalrechts. Halle:Schwetschte und Sohn, 1934.

BRANDÃO, Claudio. Introdução às ideias jurídicas da modernidade. In: BRANDÃO, Cláudio et al (Coord.). História do direito e do pensamento jurídico em perspectiva. São Paulo: Atlas, 2012.

BRITO, Alejandro Guzmán. Mos italicus y mos gallicus. Revista de derecho de la Universidad Católica de Valparaíso, Valparaíso, v. 2, 1978.

CASELLA, Paulo Borba. Presença de Francisco de Vitoria. Revista da Faculdade de Direito, São Paulo, v. LXXX, 1985.

FEUERBACH, Anselm von. Tratado de derecho penal. Buenos Aires: Hammurabi, 1989.

JESCHECK, Hans-Heirich. Lehrbuch des Strafrecht: allgemeiner teil. Berlim: Dunker \& Humblot, 1988. 
LANGELLA, Simona. Estudio introductorio. In: VITORIA, Francisco. De legibus. Salamanca: Universidad de Salamanca y Universidad de Gênova, 2010.

LEVAGGI, Abelardo. Manual de historia del derecho argentino. Buenos Aires: Depalma, 1991.

MAIHOLD, Harald. Strafe für fremde Schuld? Köln:Böhlau, 2005.

MAURACH, Reinhart; ZIPF, Heinz. Derecho penal: Parte general. Buenos Aires: Astrea, 1994.

MEDER, Stephan. Rechtsgeschichte: eine Einführung. Köln:Böhlau, 2008.

RIDDER-SYMOENS, Hilde de (editor.). A History of the University in Europe: Universities in the Middle Ages. Cambridge: Cambridge University Press, 1992.

SCHLOSSER, Hans; WILLOWEIT, Dietmar. Neue Wege strafrechtsgeschichtlicher Forschung. Köln:Böhlau, 1999.

SPINDLER, Anselm. Vernunft, Gestz und Recht bei Francisco de Vitoria In: BUNGE, Kirstin Org. Die Normativität des Rechts bei Francisco de Vitoria. Suttgart: Frommann, 2011.

STIENING, Gideon. Nach göttlichen oder menschlichen Gesetzen. In: BIESKORN, Norbert; STIENING, Gideon (Orgs.). Francisco de Vitoria 'De indis'in Intersziplinärer Perspektive. Suttgart:frommann, 2011.

STÜBEN, Joachim. Wir soll man Vitoria Übersezen? In: BUNGE, Kirstin Org. Die Normativität des Rechts bei Francisco de Vitoria. Suttgart: Frommann, 2011.

TEIXEIRA, Hélio Aparecido. Aproximações entre Francisco de Vitoria e sua crítica ao pacifismo de Lutero. Cauriensia. Extremadura: Universidad de Extremadura. 2011. Vol. VI.

VILLEY, Michel. A formação do pensamento jurídico moderno. São Paulo: Martins Fontes. 2009.

VITORIA, Francisco de. Relectio de indis. Madrid: Consejo Superior de Investigaciones Científicas (Corpus Hispanorum de Pace). 1989.

VITORIA, Francisco de. Relectio de Potestate Civili. Madrid: Consejo Superior de Investigaciones Científicas (Corpus Hispanorum de Pace), 2008.

VITORIA, Francisco. De legibus. Salamanca: Universidad de Salamanca e Universidade de Gênova, 2010. 
Recebido em: 21-3-2017

Aprovado em: 16-5-2017

\section{Claudio Brandão}

Doutor em Direito pela Universidade Federal de Pernambuco (UFPE); mestre em Direito pela UFPE; professor do Programa de Pós-graduação em Direito da Pontifícia Universidade Católica de Minas Gerais (PUC-MG); professor titular da UFPE; professor titular da Faculdade Damas da Instrução Cristã. E-mail: brandaoclaudio@hotmail.com

Pontifícia Universidade Católica de Minas Gerais. Programa de Pós-Graduação Stricto Sensu em Direito.

Av. Dom José Gaspar, 500, prédio 5, 2ํandar, sala 217 - Coração Eucarístico Belo Horizonte/MG - CEP: 30535901 
